\title{
THE IMPORTANCE OF CONSIDERING FLEET SIZE IN THE LIFECYCLE COST ANALYSIS OF PRODUCT SERVICE SYSTEMS
}

\author{
J. A. Schneider ${ }^{1, \otimes}$, M. M. Gatzen ${ }^{2}$ and I. Mozgova ${ }^{1}$ \\ ${ }^{1}$ Leibniz Universität Hannover, Germany, ${ }^{2}$ Baker Hughes, United States of America \\ $₫$ schneider@ipeg.uni-hannover.de
}

\begin{abstract}
The use of product-service systems business models is increasing in today's economy. Because the products that provide the service to the customers incur cost during their lifetime, the method of lifecycle costing finds wide-spread use. However, this paper shows the current methods have some inaccuracies when determining lifecycle costs. The methods do not consider the required number of products necessary to provide the offered service to the customers. This paper describes a new framework for lifecycle costing that includes these cost components.
\end{abstract}

Keywords: design evaluation, cost management, product-service systems (PSS), lifecycle costing

\section{Introduction}

In recent years there has been a steady increase of companies foregoing traditional business models based on the sale of physical artefacts and shifting more towards revenues generated by services provided to customers with those physical artefacts (McAloone, 2011). These business models can be defined as product-service systems (PSS), which are combinations of products, services, infrastructure and supporting networks (Goedkoop et al., 1999; McAloone et al., 2011). PSS can be classified based on different levels of service integration, with the result-oriented PSS as the one with the highest service integration. In that case only the result is sold to the customer (Tukker, 2004; Schreiber et al., 2017). These types of PSS are already in use with aircraft engine manufacturers today, as "Power-by-the-Hour" contracts, as ridesharing concepts developed by car manufactures to fulfil the need for mobility without owning a car, or in the case of the oil and gas service industry, where the drilling equipment is not sold but rather the result: the well placement. The industry partner Baker Hughes is an energy technology company which utilizes this type of PSS. One of their major segments is are the oilfield services which includes providing well placement for oil and gas. This is achieved by using drilling equipment that is developed and manufactured by Baker Hughes itself. For all this drilling equipment Baker Hughes maintains considerable fleets to ensure that any service is available to customers when necessary. Therefore result-oriented PSS fleets have been chosen as the focus of the proceeding research. Because it aligns with the business model used by the industry partner Baker Hughes.

As companies focus on increasing their profits, a minimization of their costs is always desired. In the case of a traditional business model where the sale of products is the main source of revenue, this is usually achieved by reducing the manufacturing costs of an individual product. In the case of PSS, this is not sufficient. Manufacturing costs are incurred by the company and costs for maintaining and operating the product, because the company retains ownership of the product (Kunz et al., 2013). 
These accumulation of costs over the entire lifecycle of a product (lifecycle costs) are defined as: The complete costs of a product over its complete lifetime (IEC 60050-192, 2015). Although the initial manufacturing costs are still important for the calculation of the lifecycle costs of a product, the accumulation of operation and maintenance cost is of high significance, and given a long product life will outgrow the manufacturing costs (Farr, 2011). Therefore, when developing a product for use in product-service systems, in addition to the manufacturing costs of a product, the costs generated during the operation and maintenance of the product are of high significance (Johannknecht et al., 2016a). The adoption of lifecycle costing into industry has been slow, even though it is prudent to do so, especially with regards to PSS (Lindholm and Suomala, 2004; Woodward, 1997).

The current state of research shows a variety of methods (Johannknecht et al., 2016a; Cerri et al., 2014; Emblemsvag, 2001; Woodward, 1997; Fabrycky and Blanchard, 1991; Asiedu and Gu, 1998) and even commercial standards that contain a very general approach (IEC 60300-3-3, 2017). Although these methods show approaches for calculating the lifecycle costs for a product, they all focus on the cost of individual products. With these results it is possible to calculate the cost of a product fleet. But this calculation would not display the impact different design decisions have on the required size of the required PSS fleet and consequently its entire lifecycle costs. Which is vital as companies that operate PSS own a fleet of any given product to provide the service to all customers in a timely manner and the overall fleet costs are what drives the costs that stand against the revenue that is generated. In the case of Baker Hughes, the number of identical products in operation to achieve this goal can range from 10 to 300 products. Therefore, this information should already be taken into consideration during lifecycle costing, because the number of products required (fleet size) to provide the same service to an equal number of customers has a major impact on the overall cost of the service. The calculation of fleet sizes and fleet composition is already standard for many different industries and well documented in literature. There have been publications focusing on optimization of fleet sizes as early as 1968 (Griffis, 1968). More recent research often focuses on the transport (List et al., 2003; You and Hsieh, 2014) and aviation industries (Rosskopf et al., 2014; Dožić and Kalić, 2015). These models assume a customer perspective, making optimizations with regards to which products are to be purchased and added to the respective fleets. This approach is appropriate for these cases, because they assume the product is purchased from a third party. However, in the case of PSS this is different, because the product user can also influence the design of a product to impact the size of a fleet and associated costs. Consequently, a lifecycle costing model for PSS should consider the required fleet size and the total costs incurred to provide the service to all customers, especially because the majority of the costs are accumulated during the product's lifecycle are already defined during the design phase (Bescherer, 2005; Lindholm and Suomala, 2007; Ehrlenspiel et al., 2007; Dowlatshahi, 1992). Thus, it is necessary to ensure the use of the fleet lifecycle costing model during the design phase to assist in decision making, when deciding on design alternatives, or trying to implement cost reductions. In order to enable this decision making this paper aims to develop a framework that combines aspects of lifecycle costing and fleet size calculation. So that all the interdependencies that occur between the two models can been combined into one approach which shows the overall impact on the lifecycle cost of the entire fleet. Based on the individual design changes and how they impact the different aspect of the lifecycle costs and fleet size.

\section{State of the art}

As alluded to above, the separate areas of lifecycle costing and fleet size optimization have been explored in existing literature. Therefore, the following section intends to give a short overview of these two areas and some of the relevant methods further discussed in this paper.

\subsection{Lifecycle costing}

Lifecycle costing (LCC) was initially developed for decision support in the US Department of Defence when making procurement decisions (White and Ostwald, 1976) and remains in use until today. According to Asiedu and Gu (1998) LCC can be used for a variety of different products, which is supported by a wide field of applications, while Fabrycky and Blanchard (1991) describe a hypothetical industrial use case of portfolio manager, and Johannknecht et al. (2016b) describe the actual use in the 
industrial sector with Baker Hughes with a focus on product development. In addition, many examples for LCC exist in the construction industry (Bull, 1993; Goh and Sun, 2016; Salem et al., 2003). The IEC 60050-191:2014 describes a more general approach towards LCC that allows readers to gain a general understanding of the term lifecycle costs and methods in existence to determine costs. Because the described methods are not specific, it would be necessary to adapt it to each use case. The models developed for the construction industry focus on immovable assets, so they are not applicable to the case of oil and gas drilling equipment. The IEC 60050-191:2014 is cannot be directly applied to this use case. Because the model by Johannknecht et al. (2016a) was already developed and focused on the oil and gas industry, he later shows its wider applicability (Johannknecht 2019). Consequently, this model is selected as a point of reference in this paper. Johannknecht et al. (2016b) divides the lifecycle costs into two distinct areas: capital expenditure (initial production costs) and operational expenditures (material costs, labour costs and third-party costs). As shown in Figure 1, these costs are then further divided into wear parts, consumable parts, maintenance, repairs, external repairs and external inspections.

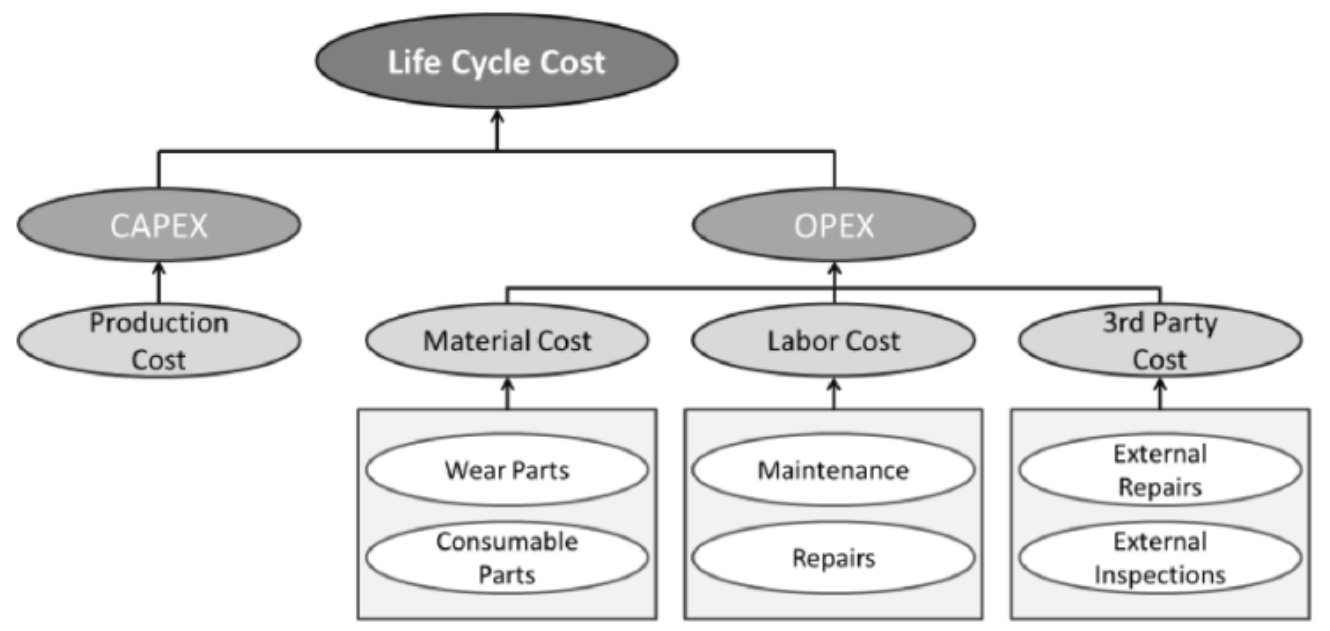

Figure 1. LCC composition (Johannknecht et al., 2016b)

The LCC of the product are then calculated as: The sum of capital expenditure plus operational expenditure, times the total time of use. For the calculation of the six components the following equations are defined by Johannknecht (2018):

$$
\begin{aligned}
& \text { Wear Parts }=\sum_{\text {omponent } 1=x}^{\text {component } n} \frac{\text { Costs of individual component } x}{\text { Estimated lifetime of part } x} \\
& \text { Consumable Parts }=\sum_{\text {component } 1=x}^{\text {component } n} \frac{\text { Costs of individual omponent } x}{\text { replacement intervall of component } x} \\
& \text { Maintenance }=\sum_{\text {component } n}^{\text {componex } 1=x} \frac{\text { Time for maintenance } * \text { labour cost }}{\text { maintenance intervall of component } x} \\
& \text { Repairs }=\sum_{\text {component } n}^{\text {compone } n} \frac{\text { Time for repair } * \text { quantity } * \text { labour cost }}{\text { repair intervall of component } x} \\
& \text { External Repairs }=\sum_{\text {component } 1=x}^{\text {component } n} \frac{\text { Costs for external repair of component } x}{\text { repair intervall of component } x} \\
& \text { External Inspections }=\sum_{\text {component } 1=x}^{\text {component } n} \frac{\text { Costs for external inspection of component } x}{\text { maintenance intervallof component } x} .
\end{aligned}
$$

Because all equations are component specific, it is possible to calculate the operational expenditures for the complete product and the operational expenditures on a component level. With this information this method enables more than a comparison of entire product designs; it identifies cost drivers enabling the targeted planning of cost-reduction measures (Johannknecht et al., 2019). In his work cost management of PSS, Soth (2011) defines three questions that have to be answered for successful cost management:

1. How much is a PSS allowed to cost?

2. What will the PSS cost and what are its cost drivers?

3. How can these costs be reduced? 
This approach provides an answer towards question 2. While the other questions are answered as well in Johannknecht's work they do not pertain to the topic of this paper and are therefore omitted.

\subsection{Fleet size optimization}

Fleet size optimizations are a common subject in area of operations research, with the goal to maximize or minimize a real-world objective, for example: profit, risk or cost. Commonly used methods are linear programming, nonlinear programming, integer programming and mixed integer programming (List et al., 2003; Rosskopf et al., 2014). These methods come with certain limitations, making them usable for a specific type of problem as shown below (Table 1). Because linear programming requires the decision variables to be real numbers, this is not feasible, if the required result is a number of non-partial products. Nonlinear programming can be eliminated by the same reasoning. This leaves the integer and mixed integer version. Purely integer programming versions can also be ignored, because prices and times can be non-integers as well as availability rates (Helber, 2014).

Table 1. Differences between programming types

\begin{tabular}{|l|c|c|c|}
\hline Method & Objective function & Constraints & Decision variables \\
\hline Linear programming & Linear & Linear & Real numbers \\
\hline Nonlinear programming & Can be nonlinear & Can be nonlinear & Real numbers \\
\hline Integer linear programming & Linear & Linear & Integers \\
\hline Mixed integer linear programming & Linear & Linear & Integers or real numbers \\
\hline Integer nonlinear programming & Can be nonlinear & Can be nonlinear & Integers \\
\hline $\begin{array}{l}\text { Mixed integer nonlinear } \\
\text { programming }\end{array}$ & Can be nonlinear & Can be nonlinear & Integers or real numbers \\
\hline
\end{tabular}

Mixed integer linear or nonlinear programming can be used for calculating the optimal fleet size of product for PSS (Helber, 2014). The choice of which programming type to use depends on the exact model implemented and how the objective functions and constraints are modelled (Helber, 2014). Additionally, other possible and easier-to-implement methods have been shown to work. For example, using a simulation-based approach to calculate the minimal number of products, of any given configuration, necessary to fulfil customer demand. This can be achieved by using plant simulation software and considering the products as materials flowing from machine to machine, which in this case represent the users, maintenance and repair visits (Johannknecht et al., 2016b). Consequently, the lowest amount of product necessary to ensure a full utilization of the user elements would be the optimal fleet size.

\section{Identification of problems}

The methods shown in section 2 are proven to work, especially in the given industry case, and give reliable results, which allow for the optimization of PSS lifecycle cost and fleet size. However, these methods have certain shortcomings. In the case of the LCC model, all operational expenditures display a relation in the same way that shows costs for the event divided by the time between events. For example an electronic component reaches the end of its life. The cost for the replacement component (dividend) has to be divided by the time between replacements (divisor).This would reflect this components impact on the operational expenditure over time. To achieve a cost reduction in this configuration, the quotient always must be lower than the previous one. There are only five cases for which this is possible:

1. The dividend grows less than the divisor

2. The dividend shrinks while the divisor remains the same

3. The dividend shrinks while the divisor grows

4. The dividend remains the same while the divisor grows

5. The dividend shrinks more than the divisor

Cases two, three and four rarely occur in real life. When they do occur, they are obviously better than the previous component they are compared against. An analysis in the form of LCC is therefore not necessary 
for those cases. Because transferring this to the example above would mean that a component would become cheaper or remain at the same cost, while simultaneously increasing its lifetime, or remaining at the same. That leaves case one and five as relevant cases for LCC. In the example presented in Figure 2, a material change in a component is considered to reduce the lifecycle costs of the drilling equipment. The Data for this stems from real world data provided by Baker Hughes but has been altered as to not reveal sensitive business information. As shown in Figure 2, case one would only be preferable if the product exceeds a run time of 1800 hours. This point of intersection is altered by the impact the change of material has on the maintenance and repair cost, as well as the costs for external inspections and repairs. In practical application, this has very rarely made a significant difference, to see result change from unfavourable to favourable, because often the wear parts quotient is not lower than before, but actually higher. For these cases to provide a benefit to the overall lifecycle costs of the product, the change would have to be offset by changes to maintenance and repair cost as well as the costs for external inspections and repairs. Although from a cost perspective it would be the most desirable to have case 5, because the initial cost would be lower as well as the costs over time making this solution appear objectively better. However, in real-world examples this might not be feasible without losing product performance, and potentially prevent achievement of all requirements. Even if this is possible, there is always the chance that it will result in growing maintenance and repair costs, as well as external inspection and repair costs. In all these cases the biggest problem is that the cost caused by changes in availability of the product for service is not considered.

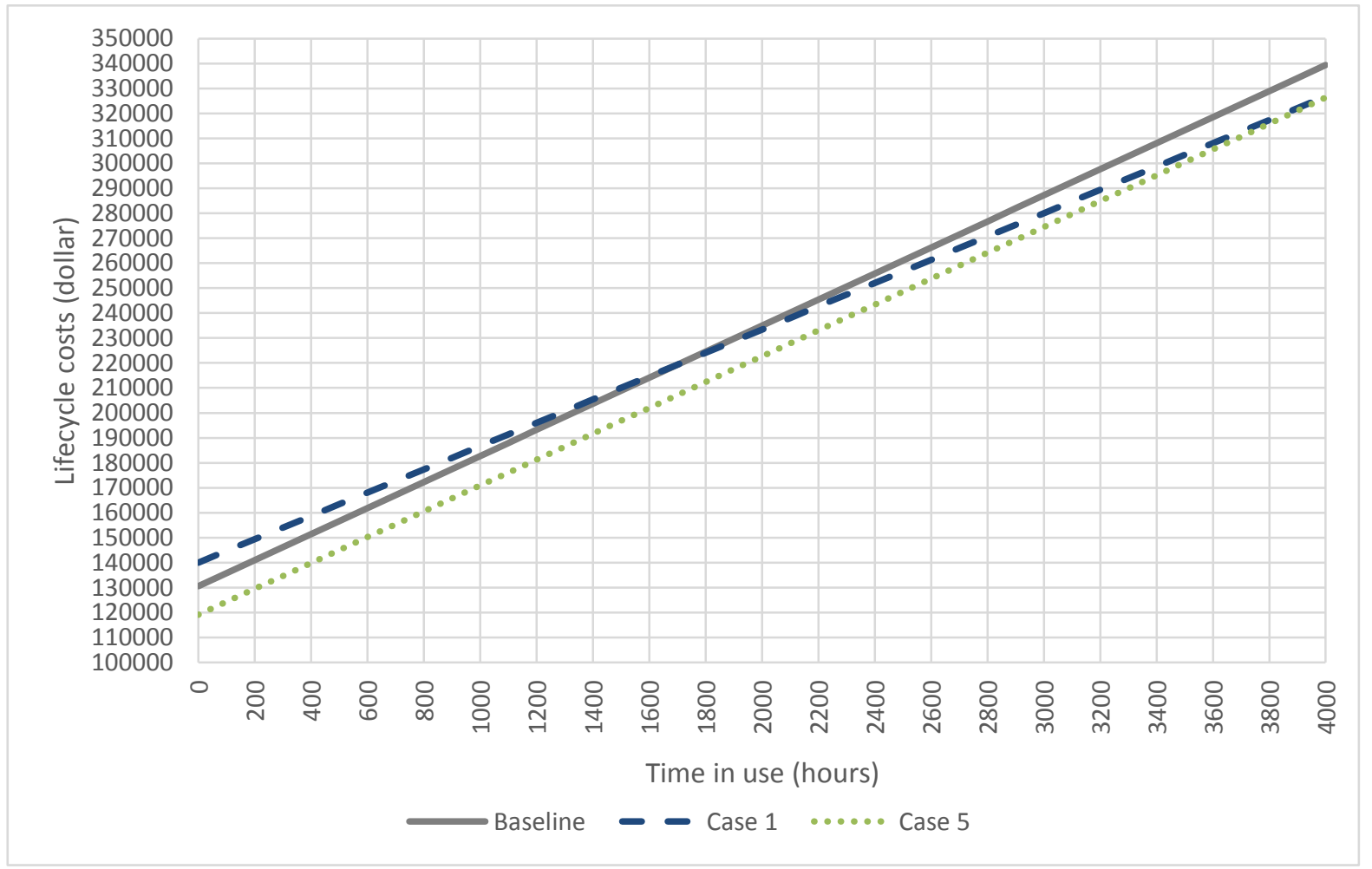

Figure 2. Comparison of price and lifetime change impact

As previously explained, the availability of an individual product directly impacts the size of the required fleet needed to fill the demand of all customers. Therefore, designing a product that provides a very high availability can have major impact on the overall costs to provide a given service to all customers. To evaluate the size of the required fleet, the methods described in section 2.2 can be used. As described by Johannknecht (2016a), the savings in capital expenditure, when comparing two alternative product designs, can be considered as opportunity costs per product. This enables comparison of the entire lifecycle costs of either product against each other, with additional consideration of costs incurred by having to own a larger fleet of products. But either of this approaches only shows that achievable optimal fleet size required for any given customer demand. 
While both lacking the ability to convey the information on why particular changes to a products design have a certain impact on the fleets lifecycle costs.

\section{Proposed solution}

To enable a more comprehensive analysis of a PSS lifecycle costs, one needs to be able to expand the LCC model to include impacts a change in product design has on the fleet size requirements. Figure 3 illustrates which information is required in the example of a company that operates PSS in the oil and gas drilling industry. The entire combination of relevant parameters is encased by the square labelled Fleet LCC. Additionally, there is a further subdivision into the areas that are impacted by this initial information. Listed first are all parameters that are required for the calculation of the capital expenditure (Capex), which are the costs of all individual components, the quantities that required, as well as all assembly costs. Overhead is not considered here, because it cannot be influenced by changing the design of the product. Demand forecasts are required to have the ability to calculate fleet sizes, because without them the most cost-efficient fleet size would be zero. The separation of this demand into regions is necessary to ensure the parameters for the operational expenditures (Opex) are allocated correctly. The largest number of parameters is connected to the Opex, with some of the parameters duplicated from Capex. The new approach uses the parameters about maintenance characteristics of the components consisting of the lifetime of a component (MTTS), the mean time between maintenances (MTBM), mean time to repair (MTTR), to determine the non-productive times of the individual products to determine their impact on the required fleet size to fill customer demands. The costs resulting from this can then be reassigned to the individual parts as an overall fleet size cost and even further to show which parameters are responsible for these costs. Furthermore, the disassembly structure is added as a new parameter to ensure all disassembly times are triggered correctly when a component needs to be exchanged, and the qualification required to repair a certain components, because not all maintenance facilities have the same repair qualification. It is also important to have information about the logistic network, to know the shipping costs and times, to show if higher complexity to repair might cause additional cost and time through shipment. The last important information with regards to the Opex, is the chosen maintenance strategy, which might impact the values for MTBM and MTTS. In case an event-based maintenance strategy is necessary, additional information about expected drilling conditions is required to determine the frequencies for MTBM and MTTS. The other parameter in this square is only necessary if a slow transition between two different product generations is to be realised, and the cost of that transition should be part of the analysis. Last of all, there are some additional inputs needed to calculate the number of required products (Tools) which is the MTTS of the entire tool: The rate at which tools become lost in hole (LIH) and therefore are lost for future use, if the cost of transition are to be considered, the rate at which the tools are exchanged (Ramp Up).

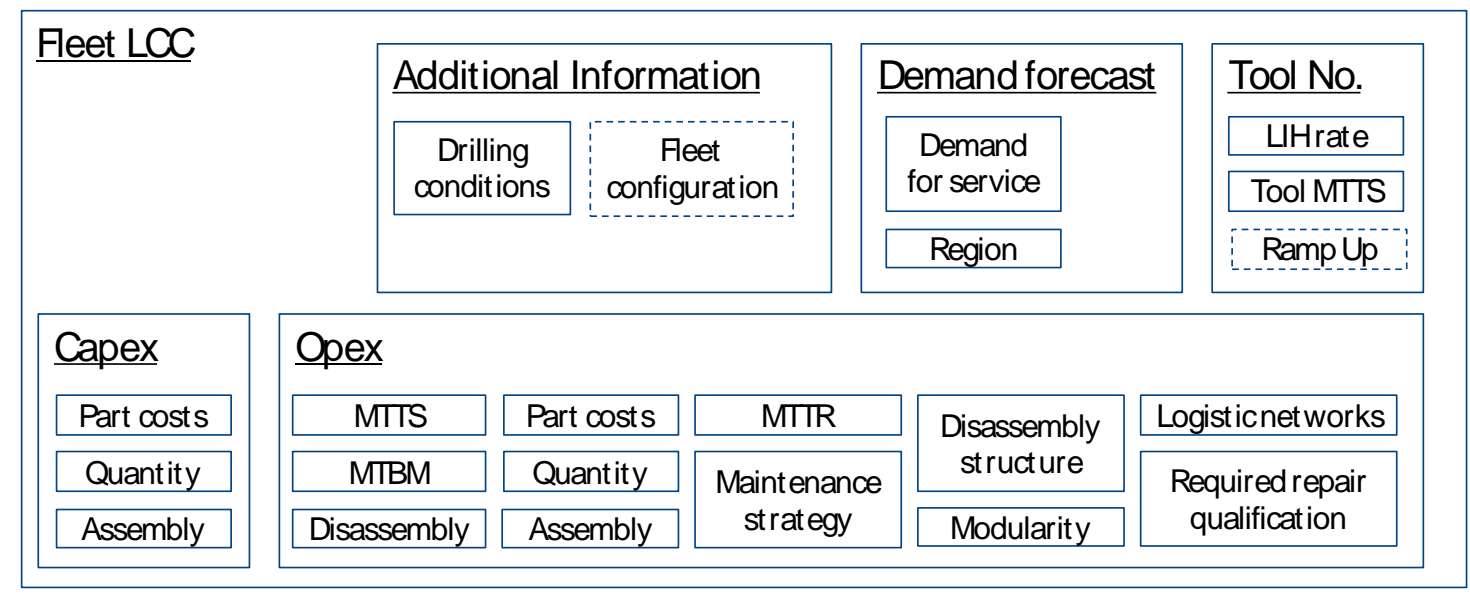

Figure 3. Information requirements for fleet LCC of PSS

With the information available, the interdependencies between them have to be modelled to ensure all cost impacts are correctly displayed. For this, the different information is clustered into four newly 
introduced modules that interact with each other, as well as the fleet LCC (Figure 4). These modules contain the data necessary for the specific aspect of the fleet LCC calculation. Although the data is needed for the module is not always available in which case the simulations contained in the modules would be used to generate the necessary data. The Tool Module contains all the parameters regarding the tool, costs of the components, quantity of the components required, assembly times and disassembly structures as well as the tool MTTS. The parameters within the module interact with one another, with regards to the fleet LCC. For example, the quantity and components' costs must be multiplied to determine the overall components' costs incurred for the tool. At the same time, the parameters interact with those from other modules. The maintenance module needs the information from the tool module to calculate the maintenance costs of the product. As a way to model these interactions, the mixed integer programming can be used for modelling the cost of the individual components and their dependencies as individual objective functions and conditions. The results of the individual components can then be passed to the objective function and the boundary conditions of the entire tool and then to the fleet to enable a total result. Solving a mixed integer problem, with so many possible variables and degrees of freedom, seems unlikely at this time for a direct optimization of products. Nevertheless, if the variables are known, the result can still be calculated, and because most of the information is already available for companies operating PSS or has to be determined to perform LCC with current methods, the additional work required for the end user is not as high as one might assume. As some of the information is inherently uncertain, like the customer demand, or in this case the drilling conditions, it is also prudent to perform a sensitivity analysis to ensure the impacts caused by changes in any of the parameters, will not lead to unacceptable changes in cost. This analysis also enables improved assessment of potential risks and enables formulating adequate risk management strategies to ensure they are kept at a reasonable level.

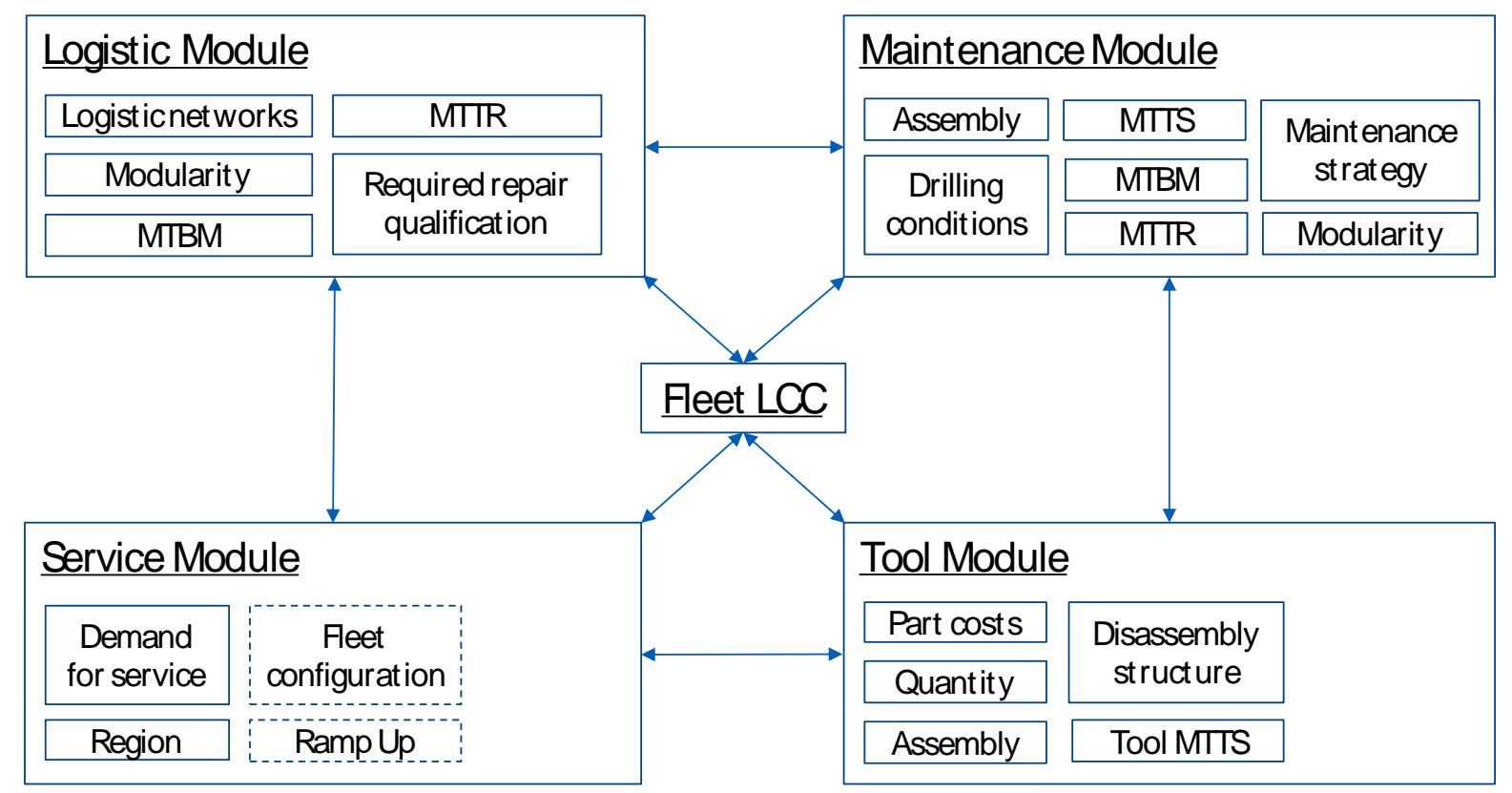

Figure 4. Interdependencies of parameters for fleet LCC of PSS

After this is completed, the costs can be accumulated into an overall lifecycle cost for the entire fleet of PSS, required to satisfy customer demand. It is also possible to identify the costs for each component, according to which module they are assigned to and then further identify the root cause of high costs. In summary, a targeted optimization of individual components is possible. A further possibility is to use the target function and boundary conditions to turn one of the parameters of a cost driver component into a decision variable, to gain an understanding how the characteristics of the component would have to change to improve its cost. In this case, it would likely be necessary to implement additional boundary conditions, to ensure no impossible optimization paths occur, like an infinite component lifetime. 


\section{Example}

Drilling tools used for servicing customers usually contain at least one pipe that houses all the required electronics (electronic sub) and other components required to ensure the functionality of the tool. At both ends, they have threads to enable a connection to other drilling tools in the bottom-holeassembly. Because these threads are connected on the drill rig in harsh field conditions, the threads must be recut after a certain number of uses. This means that potentially a part of the pipe needs to be cut off and the thread set back into the remaining pipe. Alternatively, a piece of material can be stub welded to the existing tool, to allow enough room to cut a thread. Depending on the used material, this work has to be performed more or less frequently.

Using nickel-chromium-based alloys can be useful to ensure lower maintenance and repair frequencies, as well as longer overall component life. Because these alloys in many cases fall in the previously described first case or have a larger cost increase than the increase in lifetime, LCC must be performed to evaluate whether additional investment in component cost would be worth it, under consideration of the lifecycle costs. The following data example resembles real-world cases, the numbers have been altered to only show the trend. The example compares two different product designs; one where the electronic sub is manufactured using an Inconel material and the other using lower-cost stainless steel. Cost parameters needed to calculate the different results for both designs can be found in Table 2. All other factors are assumed to be constant, for this example. The example is limited to only the key cost parameters that are required to show the impact the consideration of the fleet size has on the lifecycle costs. The fleet size cost shown in Table 2 are derived from the differences in product availability caused by the differences in repair frequencies and repair times. Which causes a larger number of stainless steel tools to be necessary to perform the same work as the Inconel tools.

Table 2. Cost parameter for the alternatives

\begin{tabular}{|l|c|c|}
\hline Design alternatives & Inconel & Stainless steel \\
\hline Capex & $\$ 150.000$ & $\$ 100.000$ \\
\hline Maintenance costs & $13 \$ / \mathrm{h}$ & $12 \$ / \mathrm{h}$ \\
\hline Repair costs & $10 \$ / \mathrm{h}$ & $8 \$ / \mathrm{h}$ \\
\hline Replacement costs & $68 \$ / \mathrm{h}$ & $60 \$ / \mathrm{h}$ \\
\hline External costs & $10 \$ / \mathrm{h}$ & $10 \$ / \mathrm{h}$ \\
\hline Transport costs & $12 \$ / \mathrm{h}$ & $14 \$ / \mathrm{h}$ \\
\hline Fleet size costs & $10 \$ / \mathrm{h}$ & $30 \$ / \mathrm{h}$ \\
\hline Total cost old Method & $\$ 756.000$ & $\$ 640.000$ \\
\hline Total cost new Method & $\$ 888.000$ & $\$ 904.000$ \\
\hline
\end{tabular}

The product in question has a usable lifetime of approximately 6000 hours before it becomes unusable and must be replaced by a new product. Therefore, the parts of the lifecycle costs that occur during the product life have to be multiplied by 6000 hours. To compare the lifecycle costs of both design alternatives according to current LCC methods the costs for transport and fleet size would be ignored. With this case the stainless steel design would be preferred with a lifecycle cost of $\$ 640.000$ in comparison to the costs of the Inconel design being $\$ 756.000$. This, as explained, completely disregards any consideration that a larger fleet of stainless steel tools is needed to enable service delivery to all customers, because the stainless steel tools individually have less productive time, considering they spend more time in transit and maintenance. This decreased productive time is primarily caused by their lower resistance to corrosive drilling fluids. If these costs are taken into consideration on an individual tool level, they change the results of the LCC. In the example, the Inconel design would now have lifecycle costs of $\$ 888.000$, but the costs of the stainless steel design would be even higher with lifecycle costs of $\$ 904.000$, resulting in a different decision. It is important to understand that this result is in part also driven by the assumption that the demand will be static in this case. With fluctuating demand, as experienced in the real world, the result could look different again. With seasonal demand, these advantages could have different impacts from season to season, and would have to be normalized. 


\section{Conclusion and outlook}

While developing a PSS, many different design decisions must be made to ensure the product used for the service can fulfil all requirements while being as cost efficient as possible. To determine the cost efficiency of a PSS, LCC methods are used to assess the cost the product will accumulate over its entire lifecycle. To make the best possible decision, it is important to ensure that the cost impacts of design changes are considered as comprehensively as possible. As shown here, it is not only important to consider the costs of any given individual product, but also how the changes in the individual components impact the necessary fleet size for service delivery and the overarching cost on a fleet level. Furthermore, the importance of assigning back the overall costs to individual components, and analysing the source of the costs, is shown to allow for targeted design optimizations.

Looking forward, further research in interdependencies is necessary, as well as investigations whether or not unspecific industry rules can be defined for this. In addition, further analysis on how the fluctuation of some of the input information's impacts the result has to be performed, to enable sensitivity analysis for the result. Lastly, the possibility of implementing the structures of mixed integer programing for optimization of individual components' characteristics shall be reviewed to determine the characteristics of a cost optimal component. With regards to this, it is vital to analyse how many components could be simultaneously optimized and how optimizing individual components, step by step, would impact the overall costs optimization of the entire product fleet. Furthermore, it is important in this context to model the additional conditions, to correctly display technical limitations of components characteristic, so solutions are found that can be implemented.

\section{Acknowledgement}

This research is supported by Baker Hughes. The funding and valuable industry insights, into the use of lifecycle costing for product-service systems, are greatly appreciated.

\section{References}

Asiedu, Y. and Gu, P. (1998), "Product life cycle cost analysis: State of the art review", International Journal of Production Research, Vol. 36 No. 4, pp. 883-908.

Bescherer, F. (2005), Established Life Cycle Concepts in the Business Environment-Introduction and terminology, Laboratory of Industrial Management Report Series.

Bull, J.W. (1993), Life cycle costing for construction, 1. ed., Blackie Academic \& Professional, London.

Cerri, D. et al. (2014), "Introduction to a Model for Life Cycle Optimisation of Industrial Equipment", In: Fukuda, S., Bernard, A., Gurumoorthy, B. and Bouras, A. (Eds.), Product Lifecycle Management for a Global Market: 11th IFIP WG 5.1 International Conference, PLM 2014, Yokohama, Japan, July 7-9, 2014, Revised Selected Papers, IFIP Advances in Information and Communication Technology, Vol. 442, Springer Berlin Heidelberg, Berlin, Heidelberg, pp. 193-200.

Dowlatshahi, S. (1992), "Product design in a concurrent engineering environment: an optimization approach", International Journal of Production Research, Vol. 30 No. 8, pp. 1803-1818.

Dožić, S. and Kalić, M. (2015), "Three-stage airline fleet planning model", Journal of Air Transport Management, Vol. 46, pp. 30-39.

Ehrlenspiel, K. et al. (2007), Cost-efficient design, Springer, Heidelberg, New York.

Emblemsvag, J. (2001), “Activity-based life-cycle costing”, Managerial Auditing Journal, Vol. 16 No. 1, pp. 17-27.

Fabrycky, W. and Blanchard, B. (1991), Life Cycle Cost and Economic Analysis.

Farr, J.V. (2011), Systems life cycle costing: Economics analysis, estimation, and management, Engineering management book series, Taylor \& Francis, Boca Raton.

Goedkoop, M. et al. (1999), "Product service systems, ecological and economic basics", Econ. Aff., Vol. 36

Goh, B.H. and Sun, Y. (2016), "The development of life-cycle costing for buildings", Building Research \& Information, Vol. 44 No. 3, pp. 319-333.

Griffis Jr. F.H. (1968), "Optimizing haul fleet size using queueing theory”, American Society of Civil Engineers Proceedings, Journal of the Construction Division, Vol. 94 No. n CO1, pp. 75-88.

Helber, S. (2014), Operations Management Tutorial, Helber, Hildesheim.

International Electrotechnical Commission (2015), International Electrotechnical Vocabulary (IEV) - Part 192: Dependability, IEC 60050-192.

International Electrotechnical Commission (2017), Dependability management - Part 3-3: Application guide Life cycle costing, IEC 60300-3-3. 
Johannknecht, F. (2018), Lebenszyklusorientiertes Kostenmanagement für Produkt-Service Systeme: Dissertation, Berichte aus dem iPeG, 2017, Band 5, PZH Verlag, Garbsen.

Johannknecht, F. et al. (2016a), "Holistic Life Cycle Costing Approach for Different Development Phases of Drilling Tools", In: International Petroleum Technology Conference, Bangkok, Thailand, 2016-11-12, International Petroleum Technology Conference.

Johannknecht, F., Gatzen, M.M. and Lachmayer, R. (2016b), "Life Cycle Cost Model for Considering Fleet Utilization in Early Conceptual Design Phases", Procedia CIRP, Vol. 48, pp. 68-72.

Johannknecht, F., Herrmann, M. and Lachmayer, R. (2019), "Kostenmanagement von Produkt-ServiceSystemen. Managing Costs of Product-Service Systems", Die Konstruktion, No. 6.

Kunz, M., Söllner, M. and Leimeister, J.M. (2013), Exploring Business Models for IT-enabled Product-ServiceSystems.

Lindholm, A. and Suomala, P. (2004), The Possibilities of Life Cycle Costing in Outsourcing Decision Making.

Lindholm, A. and Suomala, P. (2007), "Learning by costing: Sharpening cost image through life cycle costing?", International Journal of Productivity and Performance Management, Vol. 56 No. 8, pp. 651-672.

List, G.F. et al. (2003), "Robust optimization for fleet planning under uncertainty", Transportation Research Part E: Logistics and Transportation Review, Vol. 39 No. 3, pp. 209-227.

McAloone, T.C. (2011), "Boundary Conditions for a New Type of Design Task: Understanding Product/ServiceSystems", In: Birkhofer, H. (Ed.), The Future of Design Methodology, Vol. 15, Springer London, London, pp. 113-124.

McAloone, T.C. et al. (2011), "Orthogonal views on product/service-system design in an entire industry branch”, In: Culley, S.J. (Ed.), Product and systems design, DS / Design Society, Design Society, Glasgow, pp. 77-87.

Rosskopf, M., Lehner, S. and Gollnick, V. (2014), "Economic-environmental trade-offs in long-term airline fleet planning”, Journal of Air Transport Management, Vol. 34, pp. 109-115.

Salem, O., AbouRizk, S. and Ariaratnam, S. (2003), "Risk-based Life-cycle Costing of Infrastructure Rehabilitation and Construction Alternatives", Journal of Infrastructure Systems, Vol. 9 No. 1, pp. 6-15.

Schreiber, D., Gembarski, P.C. and Lachmayer, R. (2017), Modeling and configuration for Product-Service Systems: State of the art and future research.

Soth, T. (2011), Entwicklung eines Kostenmanagement-Systems für hybride Leistungsbündel, Ruhr-Universitaet Bochum.

Tukker, A. (2004), "Eight types of product-service system: eight ways to sustainability? Experiences from SusProNet", Business Strategy and the Environment, Vol. 13 No. 4, pp. 246-260.

White, G.E. and Ostwald, P.F. (1976), "Life cycle costing", Management accounting, Vol. 57 No. 7, pp. 39-42.

Woodward, D.G. (1997), "Life cycle costing-Theory, information acquisition and application", International Journal of Project Management, Vol. 15 No. 6, pp. 335-344.

You, P.-S. and Hsieh, Y.-C. (2014), "A study on the vehicle size and transfer policy for car rental problems", Transportation Research Part E: Logistics and Transportation Review, Vol. 64, pp. 110-121. 